\title{
Two Dimensional Rack Storage Fires
}

\author{
HAUKUR INGASON \\ Swedish National Testing and Research Institute (SP) \\ Box 857, S-501 15 BORÅS, Sweden
}

\begin{abstract}
Flame heights and air flows in a two dimensional rack storage were investigated. The width of the vertical flue is found to be the predominant geometrical parameter controlling the flue flow. The mass flow rate increases nearly linearly with the width. Variation of the horizontal flue heights was found to have negligible effects on the vertical flue flow. For a certain vertical flue width, the mass flow rate is found to be nearly constant independent of the heat output.
\end{abstract}

Experimental results indicate a linear relationship between the flame height and the ratio of heat output to the vertical flue width. A ratio of entrained air to the stoichiometric air requirements at the flame tip is found to be 7.5. Experiments were carried out using inert boxes and a diffusion propane line burner located at the bottom of the rack. The rack was 0.59 $\mathrm{m}$ long and between $1.14 \mathrm{~m}$ and $1.34 \mathrm{~m}$ in height ( 4 boxes). The size of the rack is about $1 / 3$ of what can be expected in a real rack storage.

KEYWORDS: Flame height, rack storage, mass flow rate, flues, line burner

\section{NOMENCLATURE}

$\mathrm{C}_{\mathrm{p}}$

g

$\mathrm{H}$

$\Delta \mathrm{H}_{\mathrm{C}}$

$\mathrm{h}$

$\mathrm{K}_{\mathrm{L}}$

$\mathrm{L}$

$\mathrm{L}_{\mathrm{f}}$

$\mathrm{L}_{\mathrm{f}}$ free

$\mathrm{m}$

$\mathrm{m}_{\mathrm{f}}$

Q

$\mathrm{Q}_{\mathrm{c}}$

$Q^{\prime}$ specific heat $(\mathrm{kJ} / \mathrm{kg} \mathrm{K})$

gravitational acceleration $\left(\mathrm{m} / \mathrm{s}^{2}\right)$

height of horizontal flue (m)

heat of combustion $(\mathrm{kJ} / \mathrm{g})$

height of rack storage $(\mathrm{m})$

entrance loss coefficient

two dimensional length (m)

mean height of the flame tip (m)

mean height of the flame tip

for a free-burning line burner (m)

air mass flow rate $(\mathrm{kg} / \mathrm{s})$

fuel flow rate $(\mathrm{kg} / \mathrm{s})$

total heat output from burner $(\mathrm{kW})$

convective heat output from burner (kW)

heat output per metre of burner

$(\mathrm{kW} / \mathrm{m})$

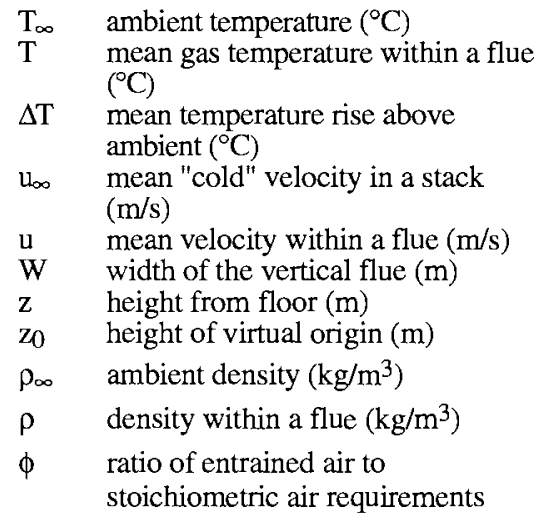

\section{INTRODUCTION}

Fire growth rate and flame propagation are dependent on how the burning material is stored. In rack storage fires this become extremely important as the upward flame propagation is usually very rapid. The flues created between adjacent pallets of stored goods tends to work as chimneys and subsequently they enhance acceleration of flames up to the ceiling. Rack storage fire protection usually consists of in-rack sprinklers which are placed at different 
elevations in the vertical flues or on the faces of the rack storage. The efficiency of such protection measures depends on the geometry of the stored goods, their height, the flue spacing and the flammability of the stored goods. The time over which the in-rack sprinkler operates is extremely important as it may be critical for control of the fire. To calculate the response time a knowledge of the flow conditions close to the sprinkler is necessary. The investigation presented here aims at outlining the mechanisms and the parameters controlling the flue flows in a two dimensional rack storage.

Many practical problems in fire engineering require a knowledge of flame heights. Correlations to determine flame heights have been presented by a number of researchers $[1,2,3,4]$. The flame height correlations are applicable to freely-burning turbulent fires and not to rack storage fires. To better understand the rapid flame spread in rack storage fires it is of interest to outline the major parameters controlling the flame heights. Due to the complexity of rack storage fires it was found appropriate to begin the investigation by using a simple experimental set-up. The experiments presented here were carried out using inert boxes in $1 / 3$ real scale. To further reduce the complexity of the study the rack was built in two dimensions.

The present study is the first phase in the development of a model to predict flow conditions within a two dimensional rack storage. Analysis of the data and description of the experimental set-up are given in this paper. Prior to the present study similar type of tests have been performed both by Ingason [5] and Karlsson et. al. [6]. These tests are to be regarded as pilot tests.

\section{EXPERIMENTS}

The following combinations of parameters were used;

$\mathrm{W}=50 \mathrm{~mm}, 75 \mathrm{~mm}, 100 \mathrm{~mm}$ with $\mathrm{H}=50 \mathrm{~mm}$

$\mathrm{W}=50 \mathrm{~mm}$ with $\mathrm{H}=75 \mathrm{~mm}$

$\mathrm{W}=50 \mathrm{~mm}$ with $\mathrm{H}=100 \mathrm{~mm}$

where $\mathrm{W}$ is the width of the vertical flue and $\mathrm{H}$ the height of the horizontal flue.

The following four heat release rates were used in each of the combinations above; $\mathrm{Q}=18.84 \mathrm{~kW}, 24.8 \mathrm{~kW}, 34.7 \mathrm{~kW}$ and $44.5 \mathrm{~kW}$

A schematic figure of the experimental arrangement is shown in Figure 1. The rack storage consisted of rectangular Navilite $\mathrm{N}$ boxes, $0.59 \mathrm{~m}$ long, $0.235 \mathrm{~m}$ high and 0.22 wide, held up by two narrow steel columns. The rack storage was two boxes wide and four boxes high. In the following each level of boxes will be called a "tier". Walls were put at each end of the boxes to create two dimensional conditions. Specially made wings were mounted at each wall in order to minimise the boundary effects of the air flowing in through the horizontal flues (see the plan view in Figure 1). These wings were made of plywood and extended $500 \mathrm{~mm}$ from the rack.

The Navilite $\mathrm{N}$ plates used to build the boxes were $9.5 \mathrm{~mm}$ thick, which means that the boxes were almost empty, except for the strips of wood used to fasten the plates together. The thermal data for the Navilite $\mathrm{N}$ is as follows; heat conductivity $0.12 \mathrm{~W} / \mathrm{m}{ }^{\circ} \mathrm{C}$, specific heat 800 $\mathrm{kJ} / \mathrm{kg}$ and density $700-780 \mathrm{~kg} / \mathrm{m}^{3}$.

Prior to the tests, the line burner was calibrated for the heat outputs used in the test series. This was done by measuring simultaneously the weight loss in a gas tube filled with propane $\left(\Delta \mathrm{H}_{\mathrm{c}}=46.45 \mathrm{~kJ} / \mathrm{g}\right)$ and the heat release rate from the burner by oxygen depletion calorimetry. The heat release rate was measured with a "furniture" calorimeter as described in the Nordtest standard NT Fire 032 [7].

During the test series the different heat outputs were manually adjusted with aid of a rotameter. A relationship had been found between the values on the rotameter and the heat 


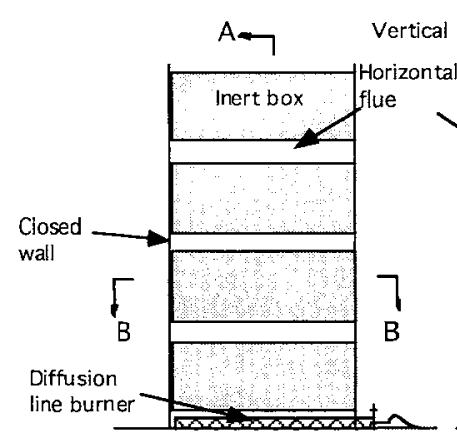

A. J

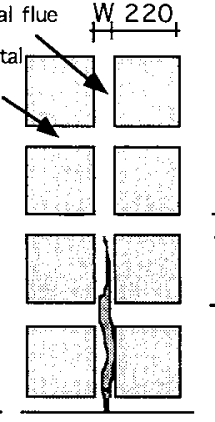

A-A

Front view

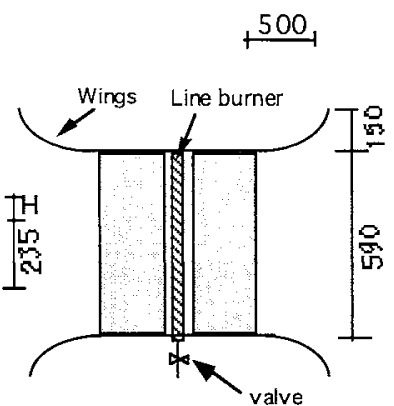

B-B

Cross section

Plan view

FIGURE 1. A 2-dimensional rack storage with non-combustable material. Dimensions are given in $\mathrm{mm}$.

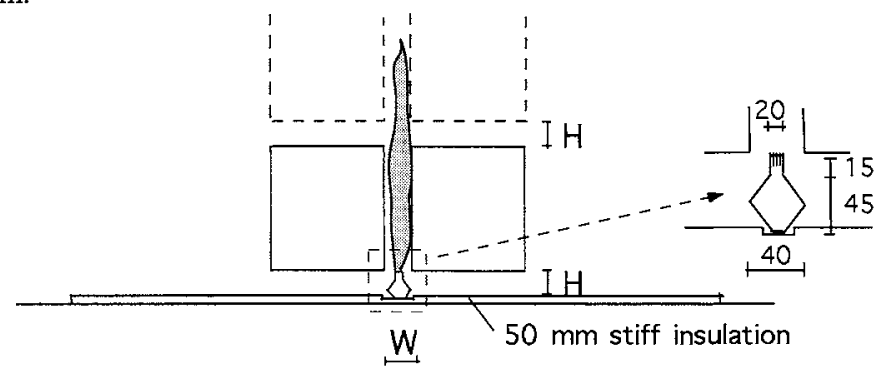

FIGURE 2. The dimensions of the line burner are given in $\mathrm{mm}$. The gas used was propane.

release rate measured by the calorimeter. It has been shown in [5] that putting the line burner inside the rack does not affect the total heat release rate compared to free burning. As this test set-up is very similar to the one presented in [5] it was thought unnecessary to measure the heat release rate from each test. The instrumentation consisted of thermocouples and bidirectional probes located at the centreline in the vertical flue at different heights. In Figure 3 the instrumentation layout is shown. To avoid influence of the bi-directional probes on each other they were mounted in a staggered form. To each bi-directional pressure flow probe $(\mathrm{D}=16 \mathrm{~mm}$ and $\mathrm{L}=32 \mathrm{~mm}$ ) was attached a type $\mathrm{K}$ thermocouple with a diameter of $0.25 \mathrm{~mm}$. The thermocouples were located about $10 \mathrm{~mm}$ from the edge of the bi-directional probe head. Within the rack a total of 8 measuring probes were used for velocity and temperature measurements whereas 4 probes were mounted above the rack. The probes used in the analysis presented here are shown in Figure 3.

Data were collected in a data acquisition system. The temperature was recorded by a 3530 ORION Data Logging Systems and stored on a Digital PDP 11/23 Plus main-frame computer. Every 10 seconds the temperatures were recorded during a period of 6 minutes (steady state tests). The pressure difference for the velocity measurements was recorded using a pressure scanner and the data were stored on a PC. The scanning time was 23 seconds. The relationship between pressure and velocity includes corrections for variation in the Reynolds number according to calibration curves reported in [8]. The results were averaged over the time interval during which the measured gas temperatures and velocities were reasonably steady. It was found that this time was about four minutes, i.e. the final four of the six 


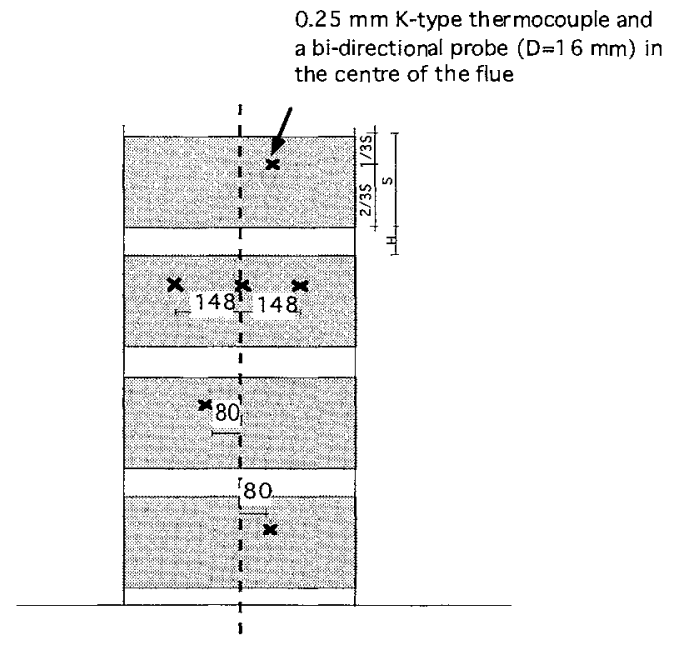

FIGURE 3. The figure shows the layout of the instruments used. All dimensions are in $\mathrm{mm}$.

minutes of the test. In the beginning of the test the walls were relatively cold causing large heat losses. After about 2 minutes the gas temperature was found to increase moderately until the end of the test. The temperature measurements were corrected for radiation effects. In [5] a formula for the correction of a $0.25 \mathrm{~mm}$ thermocouple is given.

\section{DATA ANALYSIS AND RESULTS}

The mean height of the flame tip was determined. The problem with the tests presented here is that the flames were mostly hidden by the boxes. Consequently, the determination of the flame height was rather subjective. In those cases where the mean flame tip, see Figure 4, was hidden above approximately half the box height, the flame height was determined by observe the fluctuations of the flame strips through the horizontal flue above the box. Using the highest top of the flame strips (existed periodically) as a reference a judgement was made of the distance below the top of the box were most of the flame strips were expected to exist. The distance was measured by a measuring stick placed in front of the rack. In the cases were the mean flame height was expected to be below half the box height, the flame strips were observed through the horizontal flue below the box. Using the lowest top of the flame strips (existed periodically) as a reference a judgement was made of the distance above the bottom of the box were most of the flame strips were expected to exist. If there was any doubt about the height of the flame strips an extra observation was made above the rack (see Figure 4).

The measured flame heights are presented in Table 1. The fluctuations of the flame tip within the rack were much smaller than those of the freely burning line burner. The accuracy of the visual flame height determination here is deemed to be about $+1-50 \mathrm{~mm}$. Also, for comparison, flame height data for a freely burning line burner is given. The height of the visual flame tip was averaged by eye. From Table 1 it is noticed that for the smallest flue width, $W=50 \mathrm{~mm}$, the ratio $\mathrm{L}_{\mathrm{f}} \mathrm{L}_{\mathrm{f}}$ free between the flame height in a rack storage and the height for a freely burning line burner is in the range $2.5-2.9$. At the doubled width, $\mathrm{W}=100 \mathrm{~mm}$, the corresponding figures are $1.9-2.3$. It is found from the experimental data, that the mass flow rate (entrained air) at each tier is nearly doubled when the flue width is doubled. This can be indirectly seen in Figure 6 where the dimensionless stack height $(\mathrm{z} / \mathrm{h})$ versus the ratio of 
mass flow rate to the flue width $(\mathrm{m} / \mathrm{W})$ is plotted. This increase in entrained air may explain the reduction of the ratio $\mathrm{L}_{\mathrm{f}} / \mathrm{L}_{\mathrm{f}}$ free when the flue width is increased.

$\checkmark$ estimation by eye above the rack

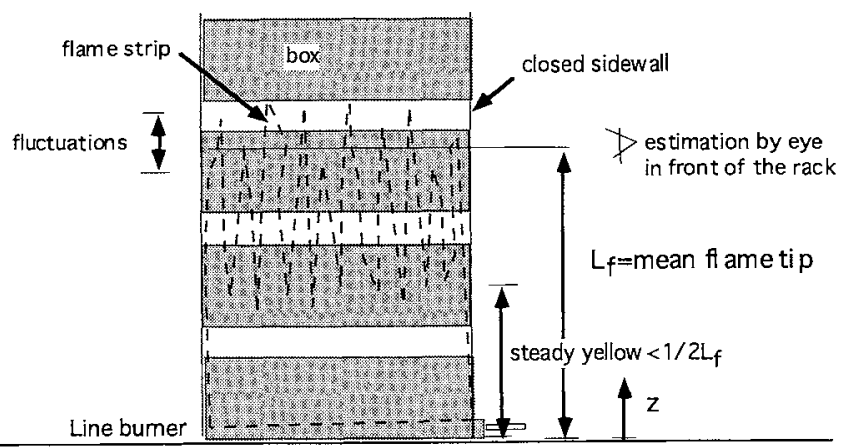

FIGURE 4. The flames are mostly hidden by the boxes and thus a subjective estimation of the mean height of the flame tip was made.

TABLE 1 The table give the observed flame heights within the rack and for a freely burning line burner. The data were obtained by "visually" averaging the height of the flame tip.

\begin{tabular}{|c|c|c|c|c|c|}
\hline $\mathrm{Q}[\mathrm{kW}]$ & $\mathrm{W}[\mathrm{mm}]$ & $\mathrm{H}[\mathrm{mm}]$ & Lf $[\mathrm{m}]$ & Lf free $[\mathrm{m}]$ & Lf/Lf free \\
\hline 18.8 & 50 & 50 & 0.60 & 0.22 & 2.7 \\
\hline 24.8 & 50 & 50 & 0.83 & 0.30 & 2.76 \\
\hline 34.7 & 50 & 50 & 0.94 & 0.38 & 2.50 \\
\hline 44.5 & 50 & 50 & 1.25 & 0.47 & 2.66 \\
\hline 18.8 & 75 & 50 & 0.54 & 0.22 & 2.45 \\
\hline 24.8 & 75 & 50 & 0.63 & 0.30 & 2.10 \\
\hline 34.7 & 75 & 50 & 0.83 & 0.38 & 2.18 \\
\hline 44.5 & 75 & 50 & 0.93 & 0.47 & 1.98 \\
\hline 18.8 & 100 & 50 & 0.51 & 0.22 & 2.30 \\
\hline 24.8 & 100 & 50 & 0.58 & 0.30 & 1.93 \\
\hline 34.7 & 100 & 50 & 0.77 & 0.38 & 2.03 \\
\hline 44.5 & 100 & 50 & 0.90 & 0.47 & 1.91 \\
\hline 18.8 & 50 & 75 & 0.63 & 0.22 & 2.86 \\
\hline 24.8 & 50 & 75 & 0.85 & 0.30 & 2.83 \\
\hline 34.7 & 50 & 75 & 0.96 & 0.38 & 2.52 \\
\hline 44.5 & 50 & 75 & 1.27 & 0.47 & 2.70 \\
\hline 18.8 & 50 & 100 & 0.63 & 0.22 & 2.86 \\
\hline 24.8 & 50 & 100 & 0.88 & 0.30 & 2.93 \\
\hline 34.7 & 50 & 100 & 0.97 & 0.38 & 2.55 \\
\hline 44.5 & 50 & 100 & 1.30 & 0.47 & 2.77 \\
\hline
\end{tabular}

\section{TEMPERATURES WITHIN THE VERTICAL FLUE}

In Figure 5 the temperature at the centreline of the vertical flue is plotted as a function of the dimensionless flame height $\mathrm{z} / \mathrm{L}_{\mathrm{f}}$ where $\mathrm{z}$ is the height of the temperature measurements above floor and $\mathrm{L}_{f}$ is the mean height of the flame tip. In the literature $[9,10]$ the temperature distribution within the flame region of a free burning axisymmetric buoyant diffusion flame 
can be found. Based on MaCaffrey's data [9], Drysdale [11] discusses the axial temperature distribution in two different flame regions. For freely burning methane fires the average centreline temperature is approximately constant $\left(\Delta \mathrm{T}=800^{\circ} \mathrm{C}\right)$ in the persistent flaming (steady yellow) region $\left(\mathrm{z} / \mathrm{Q}^{2 / 5}<0.08\right)$ but falls in the region of intermittent flaming $\left(0.08<\mathrm{z} / \mathrm{Q}^{2 / 5}<\right.$ $0.2)$ to about $320^{\circ} \mathrm{C}$ at the boundary of the buoyant plume $\left(\mathrm{z} / \mathrm{Q}^{2 / 5}=0.2\right)$. Thus, one would expect the temperature at the average flame height as defined by Zukoski et al.[12,13] (visual averaged by eye or the distance where the intermittency has declined to $1 / 2$ ) to lie in the region of 500-600 ${ }^{\circ} \mathrm{C}$. Heskestad [21] plotted a centreline temperature in logarithmic coordinates in a form attributable to MaCaffrey [9], and Kung and Stavrianidis [22], throughout the length of the plume, including the flames. The mean flame height corresponded to values in the 0.15 to 0.2 range for $\left(\mathrm{z}-\mathrm{z}_{0}\right) / \mathrm{Qc}^{2 / 5}$ and an associated temperature rise $(\Delta \mathrm{T})$ of about $500{ }^{\circ} \mathrm{C}$ was indicated. In the range $\left(\mathrm{z}-\mathrm{z}_{0}\right) / \mathrm{Q}_{\mathrm{c}}{ }^{2 / 5}<0.1$ the average centreline temperature is found to be nearly constant $\left(\Delta \mathrm{T}=900^{\circ} \mathrm{C}\right)$.

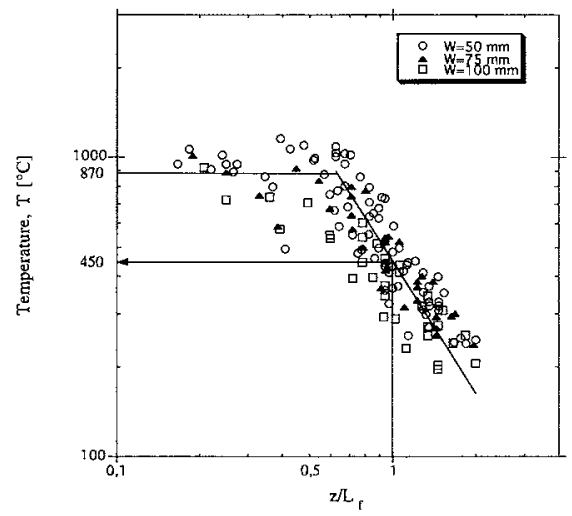

FIGURE 5. The temperature at the centreline of the vertical flue plotted as a function of the dimensionless flame height $\mathrm{z} / \mathrm{L}_{\mathrm{f}}$ for different flue widths, $\mathrm{W}$.

In Figure 5 we observe that similar tendencies are obtained here, i.e. there are two different temperature regions within the flame. Below about half the flame height the temperature is nearly constant and above it starts to decrease. The temperature $T$ at the mean flame tip (as defined in Figure 4), i.e. $\mathrm{z} / \mathrm{L}_{\mathrm{f}}=1$, is found by a curve fit (least square) for the measuring points $z / L_{f}>0.5$ to be $450^{\circ} \mathrm{C}$. By averaging the data in the region $z / L_{f}<0.5$, i.e. the approximate region with steady yellow flames, the temperature $\mathrm{T}$ is found to be $870^{\circ} \mathrm{C}$, or $\Delta \mathrm{T}=850^{\circ} \mathrm{C}$. From Figure 5 it is observed that narrower flue widths tend to give higher temperatures than wider flues.

\section{MASS FLOW RATE WITHIN THE VERTICAL FLUE}

The mass flow rate in the vertical flue can be expressed as

$m=\frac{T_{\infty} \rho_{\infty}}{T} u W L$

where $\mathrm{T}_{\infty}$ is the ambient temperature, $\mathrm{T}$ is the gas temperature and $\mathrm{u}$ is the velocity within the flue. The experimental temperatures and velocities are based on single point measurements at the centreline of the vertical flue and thus one could expect that the maximum values are 
measured. It is very difficult to make any corrections for the temperature and velocity profiles as the measuring points are relatively close to the intersections between the tiers (distortion of the flow) which might very well have great influences on these profiles. In the study it was decided not to make any corrections due to this fact. Further analysis or refined measurements are required. In Figure 6, the dimensionless stack height $(\mathrm{z} / \mathrm{h})$ versus the ratio of the calculated mass flow rate (equation (1)) to the flue width $(\mathrm{m} / \mathrm{W})$ is plotted on a logarithmic scale, where $h$ is the total height of the rack. The ratio $(\mathrm{m} / \mathrm{W})$ was chosen as it was observed from the experimental data that the mass flow rate tended to double when the flue width was doubled.

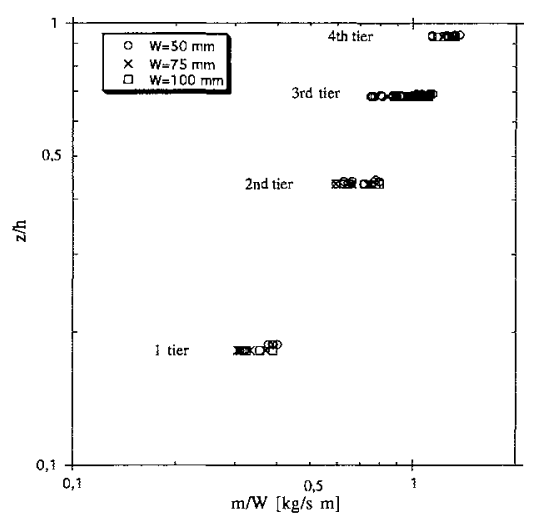

FIGURE 6. Dimensionless stack height $(\mathrm{z} / \mathrm{h})$ versus the ratio of mass flow rate to the flue width $(\mathrm{m} / \mathrm{W})$.

As can be seen in Figure 6, the data points tend to overlap although the heat outputs were varied between $18.8 \mathrm{~kW}$ to $44.5 \mathrm{~kW}$. This indicates that the mass flow rate through each tier is not changing very much for different heat outputs. Furthermore, there is clearly a relationship between the amount of air passing through each tier and the flue width, W. To investigate the reason for this we can make a very simple model of natural convection through a rectangular stack. This is analogous to the work by Heskestad and Yu [14] and Delichatsios [15] for a cylindrical stack. We assume that the stack has width $W$, length $L$ and height $h$ (see Figure 7). To simplify the model we neglect all effects of wall friction.

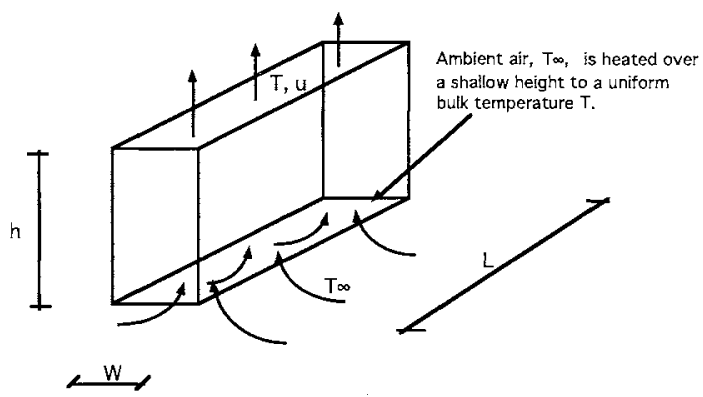

FIGURE 7. A simple model to calculate the mass flow rate within a rectangular flue. 
It is assumed that all the gas entering the base of the stack is ambient air and that combustion occurs over a shallow height just inside the stack, raising the air temperature from the ambient value, $T_{\infty}$, to the bulk value, $T$. In other words, the gas temperature is assumed to become uniform shortly after it enters the stack. A force balance can be made where the gravity force is set equal to the resistance force created at the entrance of the stack and the force due to change in momentum of the heated gas inside the rack,

$$
\left(\rho_{\infty}-\rho\right) g h W L=1 / 2 \rho_{\infty} u_{\infty}^{2} W L\left(K_{L}+1\right)+\rho_{\infty} u_{\infty}^{2} W L\left(T / T_{\infty}-1\right)
$$

$K_{L}$ is the entrance loss coefficient for the stack $\left(K_{L}=0.5\right), u_{\infty}$ is the "cold" velocity created by the draft in the stack, $\rho$ is the density within the stack, $\rho_{\infty}$ is the ambient density, $m$ is the mass flow rate ( $\left.m=\rho_{\infty} u_{\infty} W L\right)$ inside the stack and the second term on the right hand side of equation (2) is obtained from $m\left(u-u_{\infty}\right)$. The relationship between the "cold" velocity $u_{\infty}$ and the velocity $u$ within the stack is $u_{\infty}=u \frac{T_{\infty}}{T}$ (continuity). Other parameters are defined in Figure 7. With aid of equation (2), the "cold" velocity can be obtained,

$$
u_{\infty}=\sqrt{\frac{\left(1-\frac{T_{\infty}}{T}\right) g h}{\frac{T}{T_{\infty}}-\frac{1}{2}+\frac{K_{L}}{2}}}
$$

where the ideal gas law ( $\rho=T_{\infty} \rho_{\infty} / T$ ) has been used. If equation (3) is plotted for various values of $\mathrm{T}\left(100^{\circ} \mathrm{C}<\mathrm{T}<800^{\circ} \mathrm{C}\right)$ the velocity $\mathrm{u}_{\infty}$ is found to vary by less that $20 \%$. This means that the cold velocity is nearly constant for the expected temperature range within the stack. Furthermore, it is noticed that the "cold" velocity is independent of the vertical flue width, W. As the "cold" velocity is nearly a constant for most temperatures, and thus most heat outputs, the mass flow rate $\left(m=\rho_{\infty} u_{\infty} W L\right)$ divided by the width $W$ can be expected to be nearly constant. This may explain the overlapping of the data at each tier in Figure 6 . In that case we can expect the flow at each tier in the rack to be determined in a similar way as for a single stack. A relationship between temperature $T$ and heat output $Q$ can be obtained from the energy equation,

$$
Q_{c}=m C_{p}\left(T-T_{\infty}\right)
$$

where $m=\rho_{\infty} u_{\infty} W L$. With aid of equations (3) and (4) we can plot the ratio of mass flow rate to the width $(\mathrm{m} / \mathrm{W}$ ) versus the total heat output (Q) (see Figure 8 ) by varying the temperature (T) from 20 to $800^{\circ} \mathrm{C}$ (corresponding to $0-60 \mathrm{~kW}$ ). In the calculations we have assumed $Q_{c}=0.7 \mathrm{Q}$, a stack height $\mathrm{h}$ of $1.14 \mathrm{~m}$ (which is the height of the experimental set-up for $\mathrm{H}=50 \mathrm{~mm}$ ), an ambient temperature $\mathrm{T}_{\infty}=20^{\circ} \mathrm{C}$ and $\mathrm{C}_{\mathrm{p}}=1000 \mathrm{~J} / \mathrm{kg}^{\circ} \mathrm{C}$. As can be seen in Figure 8 these results verify the tendency of the mass flow rate to be nearly constant independent of the heat output (within the range 6 to $60 \mathrm{~kW}$ ). If we plot the experimental data obtained at the highest tier, were all the air has been entrained, we achieve remarkably good agreement between this very simple model and the experiments. The calculation results and the experimental data are shown in Figure 8.

The simple model applied here presumes that all the entrainment occurs at the lowest level (at the bottom of the stack) and not stepwise, as in the experiments. Yet, these results encourage the development of more sophisticated model which take into consideration the stepwise entrainment through the horizontal flues. Thus, mass flow rate, temperature and velocity at each tier can be calculated and presumably the flame height within the rack. 


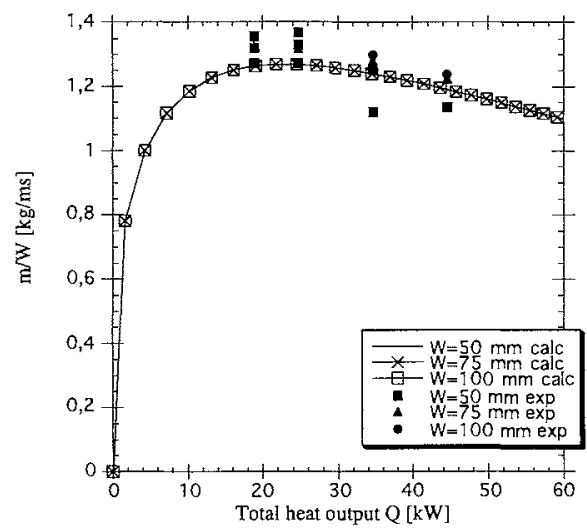

FIGURE 8. Mass flow rate divided by flue width (m/W) versus total heat output $\mathrm{Q}$.

Experimental data are plotted for comparisons at the highest tier. The plot show that the mass flow rate becomes nearly constant independent of the heat output $(6<\mathrm{Q}<60 \mathrm{~kW})$.

\section{THE FLAME HEIGHT}

We can rewrite equation (4) as follows,

$\frac{Q}{W}=\frac{\rho_{\infty} C_{p}}{0.7}\left(T-T_{\infty}\right) u_{\infty}$

where $Q^{\prime}=Q / L$ is the heat output per metre. We can expect the following relationship, $Q^{\prime} / W=$ $\mathrm{f}(\Delta \mathrm{T})$, from equation (5) because $\mathrm{u}_{\infty}$ is nearly conserved for most temperatures

$\left(100<\mathrm{T}<800^{\circ} \mathrm{C}\right)$. Furthermore, we notice from Figure 5 that the height of the flame tip tends to correspond to a certain temperature difference $\Delta \mathrm{T}$ and subsequently we can expect $\mathrm{L}_{\mathrm{f}}$ to be proportional to $\mathrm{Q}^{\prime} / \mathrm{W}$, or more generally, $\mathrm{L}_{\mathrm{f}}=\mathrm{f}\left(\mathrm{Q}^{\prime} / \mathrm{W}\right)$. To investigate this hypothesis we can plot $\mathrm{L}_{\mathrm{f}}$ versus $\mathrm{Q}^{\prime} / \mathrm{W}$ using the experimental data. The results are shown in Figure 9, where we observe a tendency to a linear relationship between $\mathrm{L}_{\mathrm{f}}$ and $\mathrm{Q}^{\prime} / \mathrm{W}$. A curve fit of data gives the following equation,

$$
L_{f}=0.307+6.15 E-4\left(\frac{Q^{\prime}}{W}\right)
$$

Thus, in a two dimensional system with a constant geometrical width the height of the flame tip tends to increase linearly with the heat output.

\section{AIR ENTRAINED AT THE TIP OF THE FLAME}

For open buoyancy-controlled diffusion flames Heskestad [1] assumed that the flame extends to a height where the total flux of air entrained at lower levels is just sufficient to complete the combustion reactions. The air demand from the surroundings is proportional to the stochiometric requirements of the pyrolysis gases

$m \propto m_{f} r$ 


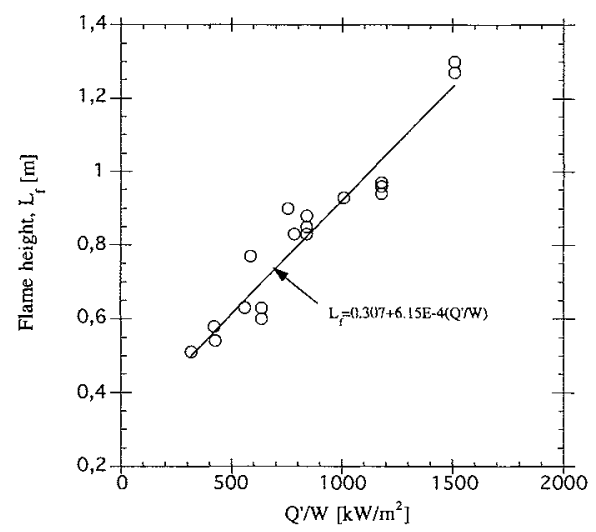

FIGURE 9. The mean height of the flame tip, $\mathrm{L}_{\mathrm{f}}$, plotted as a function of $\mathrm{Q}^{\prime} / \mathrm{W}$.

where $m$ is the total mass-entrainment rate of air below the level of the flame tip, $m_{f}$ is the pyrolysis or mass burning rate and $\mathrm{r}$ is the stoichiometric mass ratio, air to volatiles. The proportionality constant will be greater than unity, because much of the air entrained never participate in the combustion reactions. According to Delichatsios [16], the air entrainment rate can be as much as ten times the stoichiometric requirements for buoyant turbulent diffusion flames (based on measurements presented in [17,18]. There are two major differences in the present study and earlier studies $[1,16,17,18]$, namely, the air is entrained stepwise (through the horizontal flues) and the flow is bounded by solid boundaries (walls). Nevertheless, it is of interest to determine the ratio of entrained air to the stoichiometric air requirements at the mean flame tip from the experiments. The ratio of entrained air to stoichiometric air requirements for complete combustion (air-to-fuel stoichiometric fraction $[19,20]$ or "equivalence ratio" [14]) is defined as

$\phi=\frac{m}{m_{f} r}$

This ratio can be determined from the experiments since we know the mass flow rates and the total heat output. The mass burning rate $m_{f}$ in equation (8) can be found from

$m_{f}=\frac{Q}{\Delta H_{c}}$

where $\mathrm{Q}$ is the total heat release rate and $\Delta \mathrm{H}_{\mathrm{c}}$ is the heat of combustion per unit mass of the fuel $\left(\Delta \mathrm{H}_{\mathrm{c}}=46.45 \mathrm{~kJ} / \mathrm{g}\right.$ for propane). If we combine equations (8) and (9) and use mass flow rates and flame heights from the experiments we obtain the results presented in Figure 10.

Apparently, $\phi$ varies considerably depending on the flue width. For the widest flue, $W=100$ $\mathrm{mm}, \phi$ is found (by curve fit) to be approximately the same at the flame tip ( $\left.\mathrm{z} / \mathrm{L}_{\mathrm{F}}=1\right)$ as for free flames (16), or $\phi=10$, whereas for the smallest width, $\mathrm{W}=50 \mathrm{~mm}, \phi$ at $z / \mathrm{L}_{\mathrm{f}}=1$ is 6 . For $\mathrm{W}=75 \mathrm{~mm} \phi$ at $\mathrm{z} / \mathrm{L}_{\mathrm{f}}=1$ is 7.6 . The reason for this variation is not known but a possible explanation is that the temperature and velocity profiles are not uniform for the tested widths. This may be reflected in the values of the mass flow rates (based on single point 


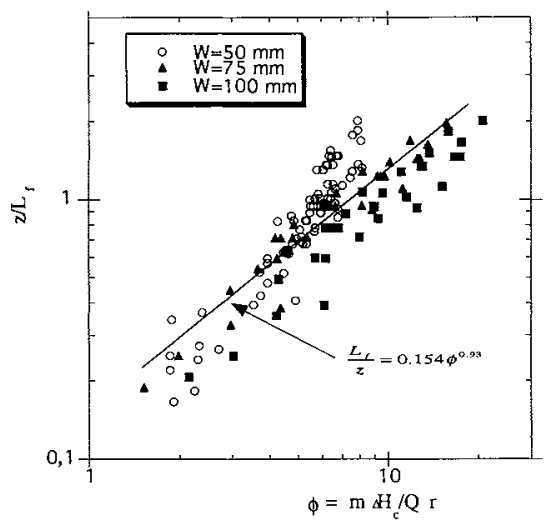

FIGURE 10. The dimensionless flame height $\left(\mathrm{z} / \mathrm{L}_{\mathrm{f}}\right)$ versus the ratio of entrained air to the stoichiometric requirements $\left(\phi=\mathrm{m} \Delta \mathrm{H}_{\mathrm{c}} / \mathrm{Q} \mathrm{r}\right)$ determined from the experiments.

measurements of temperature and velocity) used for determination of $\phi$. These results require further analysis where corrections of the single point measurements should be made.

Nevertheless, a curve fit (see Figure 10) was made for all the data points and the value at the mean flame tip is found to be 7.5 which is $25 \%$ less than the ratio found for free flames.

\section{CONCLUSIONS}

Effects of different flue widths on flame heights and air flows in a two dimensional rack storage were investigated. The width of the vertical flue is found to be the predominant geometrical parameter controlling the flue flow. The mass flow rate increases nearly linearly with the width. Variation of the horizontal flue heights was found to have negligible effects on the vertical flue flow. For a certain vertical flue width, the mass flow rate is found to be nearly constant, independent of the heat output.

An empirical correlation for flame height is given showing a linear relationship between the mean flame height $\mathrm{L}_{\mathrm{f}}$ and the ratio of the total heat output per metre to the flue width $\left(\mathrm{Q}^{\prime} / \mathrm{W}\right)$. The experiments indicates that the flame tip corresponds to a certain temperature which is found to be about $450^{\circ} \mathrm{C}$. The temperature distributions along the flame height obtained in the case with a rack storage are found to be similar to freely burning fires. Below about half the flame height, $\mathrm{z} / \mathrm{L}_{\mathrm{f}}<0.5$, i.e. the approximate region with steady yellow flames, the temperature tends to be constant. An averaging of the data yields a temperature of $870^{\circ} \mathrm{C}$. Above about half the flame height, $\mathrm{z} / \mathrm{L}_{\mathrm{f}}>0.5$, the temperature starts to decrease. It is also found that narrower flue widths tend to give higher centreline temperatures than wider flues.

The ratio of entrained air to the stoichiometric air requirements at the flame tip was found to be 7.5 . 


\section{ACKNOWLEDGEMENT}

This part of the project was sponsored by the Swedish Research Board (BRANDFORSK) which is gratefully acknowledged. A co-operation between Lund University (LTH) and SP was established at an early stage of the project. Special thanks to Dr. Bror Persson (SP), Dr. Göran Holmstedt (LTH) and Dr. Gunnar Heskestad (Factory Mutual Research Corporation) for their advise and encouragement.

\section{REFERENCES}

1. Heskestad, G., Peak Gas Velocities and Flame Heights of Buoyancy-Controlled Turbulent Diffusion Flames, 18 th Symposium (International) on Combustion, The Combustion Institute, 1981, p. 951-960.

2. Thomas, P.H., Combustion and Flame 4, 381 (1960).

3. Thomas, P.H., Webster, C.T., and Rafetery, M.M., Combustion and Flame 5, 359 (1961).

4. Zukoski, E, in Fire Safety Science, Proceedings of the First International Symposium on Fire Safety Science, Hemisphere, New York (1984).

5. Ingason, H., Rack Storage Fires, Pilot Study, SP-AR Report 1993, Technical Note, To be published, Borås, Sweden.

6. Karlsson, B., Thomas, P.H, and Holmstedt, G., Flame sizes in a small scale stack: Pilot experiments, Department of Fire Safety Engineering, Lund University, To be published in 1993, Sweden.

7. Upholstered Furniture: Burning Behaviour-Full Scale Test (NT Fire 032), NORDTEST, Helsinki, Finland (1987).

8. McCaffrey, B.J. and Heskestad, G., Combustion and Flame 26, 125-127, 1976.

9. MacCaffrey, B. J., Purely Buoyant Diffusion Flames: Some Experimental Results, National Bureau of Standards, NBSIR 79-1910, 1979.

10. Cox, G. and Chitty, R., Combustion and Flame 60: 219-232 (1985).

11. Drysdale, D. D., An Intr. to Fire Dynamics, p.134, A Whiley-Interscience Publication 1992.

12. Zukoski, E. E., Kubota, T. and Cetegen, B., Fire Safety Journal , 3, 107-121, 1981.

13. Zukoski, E. E., Kubota, T. and Cetegen, B., Entrainment in the Near Field of Fire Plumes, California Institute of Technology, Daniel and Florence Guggenheim Jet Propulsion Center, August 1981.

14. Heskestad, G. and Yu, H-C., Fire Protection of Combustible Stacks and Mine Shafts, Phase I: Exposure-Fire Environment and Suppression, FMRC J.I. OFON7.RA/OEOE1.RA, 070(A), Prepared for United States Department of the Interior Bureau of Mines, FMRC, Norwood, Massachusetts, USA, October, 1982.

15. Delichatsios, M.A., Fire Protection of Fiberglass-Reinforced Plastic Stacks and Ducts, Interoffice Correspondence to File, Serial No. 22493, FMRC, USA, Octorber, 1975.

16. Delichatsios, M.A., Air Entrainment into Buoyant Jet Flames and Pool Fires, The SFPE Handbook of Fire Protection Engineering, Section 1/Chapter 19, SFPE, NFPA.

17. B.M. Cetegen, E.E. Zukoski, and T. Kubota, Comb. Sci. and Tech., 39, 305 (1984).

18. Delichatsios, M.A. and Orloff, L., Entrainment Measurements in Turbulent Buoyant Jet Flames and Implications for Modeling, 20th Symp. (Int.) on Comb., Pittsburgh (1984).

19. Tewarson, A., In 20th International Symposium on Combustion, The Combustion Institute, Pittsburgh, PA, USA, 1984, p. 1555.

20. Yu, H-Z., Fire Safety Journal 20 (1993) p. 175-181.

21. Heskestad, G., Fire Safety Journal, 7, (1984) p. 25-32.

22. Kung, H-C, and Stavrianidis, P., Buoyant Plumes of Large-Scale Pool Fires, Proc. 19th Symposium (Int.) on Combustion, The Combustion Institute, Pittsburgh, 1982. 